\title{
THE GENETIC SITUATION CONCERNING FERMENTATION IN YEASTS
}

\author{
Ö. WINGE \\ Carlsberg Laboratory, Valby, Copenhagen
}

Received 9.v.52

THE knowledge of the genes in yeasts which are responsible for fermentation of different sugars is now so advanced that we are able to form an idea of the general principles according to which fermentative ability is inherited.

In yeasts as in several other fungi tetrad analyses are possible, since in many cases 4-spored asci are formed and the spores are easily isolated and grown separately. Hence the segregations from artificially produced hybrids between species with different fermentative abilities may be studied. In most yeast species, however, linear tetrads similar to those occurring in Neurospora and several other fungi are not formed, as the ascus is very often ellipsoidal. This is, for example, the case in many Saccharomyces types, while in Schizosaccharomyces Pombe Leupold (1950) had no difficulty in studying ordered tetrads since the asci in this species are cylindrical and the spores arranged in a single row.

The most important fact that has been established is that the genes in question are inherited in a strictly mendelian manner and that apparently all genes for fermentation are dominant. Another fact is that several (polymeric) genes for the fermentation of a given sugar may be present in one yeast (Winge and Roberts, 1948, 1950).

\section{GALACTOSE FERMENTATION}

A simple mendelian segregation is observed when the progeny of the hybrid Saccharomyces cerevisiae $\times S$. Chevalieri is analysed. The former species is able to ferment galactose rapidly (i.e. within $\mathrm{I}-2$ days), while the latter is a slow fermenter, which was originally described as unable to ferment galactose. It ferments, however, galactose after an adaptation period of 4-6 days. The hybrid segregates out from every ascus two spores giving rise to rapidly fermenting cultures and two giving rise to slowly fermenting cultures. Exactly the same result is obtained when the progeny of the hybrid S. Italicus $\times S$. Chevalieri is analysed; here it is $S$. Italicus which is the rapid fermenter. In our own experiments we have not made crosses with species which were entirely unable to ferment galactose, but Lindegren (1949 and earlier) mentions a segregated type which could not adapt to galactose-fermentation, and the same type has later been mentioned by Kilkenny and Hinshelwood (195I). A hybrid between this type and S. cerevisiae gave also a strictly mendelian ratio of 2 fermenters : 2 non-fermenters. As we know, some 
species have been described, as for example $S$. Bayanus, which are unable to ferment galactose.

It is still uncertain whether three alleles exist, $G$ for rapid fermentation, $\mathrm{g}_{\mathrm{s}}$ for slow fermentation and $\mathrm{g}$ for no fermentation, or whether they are non-allelic. A hybrid $\mathrm{Ggg}_{\mathrm{s}} \mathrm{g}_{\mathrm{s}}$ would of course segregate out 2 rapid : 2 slow fermenters-i.e. it would give the same segregation as a $\mathrm{Gg}_{\mathrm{s}}$ type in which $\mathrm{G}$ and $\mathrm{g}_{\mathrm{s}}$ were alleles.

It has been claimed by Lindegren and his co-workers that our $\mathrm{g}_{\mathrm{s}}$-gene for slow fermentation of galactose does not actually exist, but that a non-fermenter gene, $g$, mutates to $G$ during the fermentation experiment. Our $\mathrm{g}_{\mathrm{s}}$-type should therefore represent a mixture of Gand g-cells. It has, however, been made sufficiently clear that this is not the case; Spiegelman, Sussman and Pinska (1950), Spiegelman (1950) and Kilkenny and Hinshelwood (195r) were able to verify our statement that it is not a question of mutation but of long-term adaptation, as we had originally termed the phenomen (Winge and Roberts, I948). Spiegelman and his collaborators, however, claim, that only a few of the cells of a culture can adapt to galactose fermentation. In their opinion some cytoplasmic units are active during adaptation. As the problem of adaptation has no direct relation to inheritance, I shall not go into details regarding this interesting subject.

\section{MALTOSE FERMENTATION}

It has been shown (Winge and Roberts, I948, I950a) that in Saccharomyces cerevisiae (strain "Yeast Foam" from U.S.A.) not less than three genes for maltose fermentation are present. We have called them $\mathbf{M}_{1}, \mathbf{M}_{2}$ and $\mathbf{M}_{3}$. A hybrid between this yeast and $S$. Chevalieri, which is unable to ferment maltose, will yield a surplus of fermenters from single spore cultures. We have shown that the fermenters and nonfermenters are segregated out in ratios which are in accordance with the assumption that the M-genes are situated at a sufficient distance from the centromeres of the respective chromosomes so that there is $50 \%$ crossing-over between the genes and their centromere. The three M-genes are not linked to each other. Therefore a triple hybrid $M_{1} m_{1} M_{2} m_{2} M_{3} m_{3}$ will segregate fermenters and non-fermenters at a ratio of $7 \mathrm{M}$ : Im and the tetrad analyses will show $52.8 \%$ asci segregating as $4 \mathrm{M}: \mathrm{om}, 44.4 \%$ segregating as $3 \mathrm{M}: \mathrm{Im}$, and only $2 \cdot 8 \%$ asci segregating as $2 \mathrm{M}: 2 \mathrm{~m}$. A doubly heterozygotic hybrid obtained through back crossing will segregate out fermenters and non-fermenters in the proportion of $3: 1$, and the tetrad analyses will show $16.7 \%$ asci segregating as $4 \mathrm{M}: \mathrm{om}, 66.7 \%$ segregating as $3 \mathrm{M}: \mathrm{rm}$, and $16.7 \%$ segregating as $2 \mathrm{M}: 2 \mathrm{~m}$. Our findings are in full agreement with these ratios. Our triply heterozygotic hybrid yielded the following ratios:

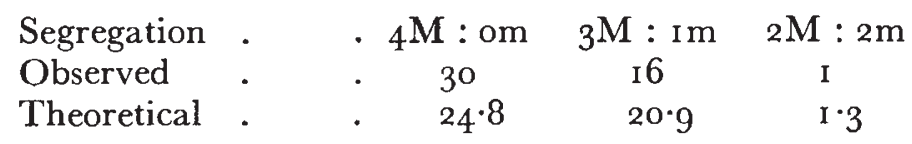


Our doubly heterozygotic hybrid yielded the following ratios:

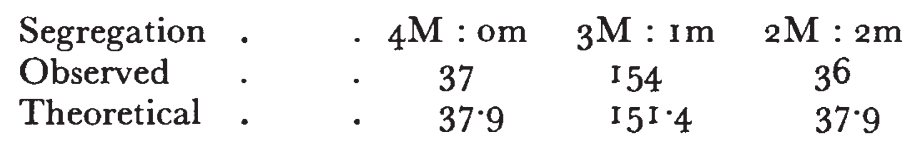

To prove fully the correctness of this theory, it was necessary to isolate each of the three M-genes by backcrossing spores from the triple hybrid to the recessive $S$. Chevalieri. We succeeded in this and have produced a number of yeast types containing $M_{1}$ alone, others with $\mathbf{M}_{2}$ alone, and several yeast types which only possess $M_{3}$. It is easily established whether $M_{1}, M_{2}$ or $M_{3}$ is present in a yeast, since a cross between two yeast types with different M's will give a doubly heterozygotic hybrid, while the crossing of two yeasts with identical M's will yield a non-segregating hybrid, the offspring of which will all be fermenters.

It is quite interesting that a new $\mathbf{M}$-gene, designated $\mathbf{M}_{4}$, was obtained through irradiating a recessive non-fermenter (Winge and Roberts, 1950). It arose as a heterozygotic, segregating $2 \mathrm{M}: 2 \mathrm{~m}$ in each ascus, as expected, and a priori we supposed that this $M$ would turn out to be either $\mathbf{M}_{1}$ or $\mathbf{M}_{2}$ or $\mathbf{M}_{3}$. By crossing the new M-type to $M_{1}, M_{2}$ and $M_{3}$ we found, however, that in all cases a double heterozygote was obtained. Hence the new M-gene was not identical with any of the three old $\mathbf{M}$-genes, and was accordingly called $\mathbf{M}_{4}$. Later on the same $\mathrm{M}_{4}$-gene arose spontaneously from the same non-fermenting culture.

As the experiments distinctly show that the origin of $\mathbf{M}_{4}$ did not involve the mutation of an inhibitor gene masking the effect of an already existing $\mathbf{M}_{4}$-gene, we favour the idea that a hypothetical "progene ", ineffective but closely related chemically to $M_{4}$, may already have been present in the non-fermenting yeast type. This ineffective gene may have been altered through a single mutational step to a maltose fermenting gene, and thus may have occurred spontaneously or through irradiation.

The fact that the existence of not less than four genes for maltose fermentation has been demonstrated compels one to question whether they are biochemically identical. It might seem easy to compare the effect of the four M-genes on a series of sugars, but if certain other fermenter genes are also present in the yeast types, it is necessary to eliminate them before the effect of the M-genes can be tested. As an example we had in our $\mathbf{M}_{2}$-types a gene, $\mathbf{R}_{1}$, for raffinose fermentation; this $\mathrm{R}$-gene is responsible not only for the splitting and partial fermentation of raffinose but also for the fermentation of sucrose. Consequently it is impossible to state whether $\mathbf{M}_{2}$ is able to ferment sucrose (in addition to maltose) as long as $R_{1}$ is present. It is necessary to produce a yeast type containing $M_{2}$ but lacking $R_{1}$ in order to establish whether or not $M_{2}$ is responsible for sucrose fermentation.

At present only $M_{1}$ and $M_{2}$ have been investigated in this way, and 
the results have shown (Winge and Roberts, 1952) that the two genes are biochemically different; $\mathbf{M}_{1}$ is sucrose as well as maltose fermenting while $\mathrm{M}_{2}$ is only maltose fermenting. In other words $M_{1}$ is a gene for the production of $\alpha$-glucosidase while $M_{2}$ is a gene for the production of maltase. The problem of an M-gene being able to ferment both sugars has been previously discussed by Gilliland (I 949), who regarded the gene which we have called $M_{1}$ as a gene responsible for the production of $a$-glucosidase.

Of course not all maltose fermenting yeast species contain as many as three or four M-genes. Saccharonyces Italicus, for example, is a maltose fermenter, and Gilliland (l.c.) demonstrated that it possessed only one M-gene pair. He crossed $S$. Italicus to the non-fermenting species $S$. Chevalieri and found that the hybrid regularly segregated out 2 fermenters : 2 non-fermenters from each of 20 asci. Later on Dr Roberts and I $\left(195^{\circ} b\right)$ identified this $\mathrm{M}$-gene of $S$. Italicus with our $\mathbf{M}_{1}$ gene in $S$. cerevisiae.

It would be interesting to ascertain whether $\mathbf{M}_{3}$ and $\mathbf{M}_{4}$ are biochemically different from $\mathbf{M}_{1}$ and $\mathbf{M}_{2}$. Lindegren, who was the first to observe segregation with respect to maltose fermentation, maintains (1949, page 26-5) that "asci do not follow any regular behaviour", and he claims to have frequently observed non-mendelian ratios, as, e.g., I M : $3 \mathrm{~m}$. According to Lindegren and his colleagues (e.g. Mundkur, I $949 a, b)$ deviating ratios are explained by "gene-conversion". We have never observed non-mendelian ratios or any sign of "geneconversion". We have, however, pointed out several sources of error when yeast hybrids are analysed; these may involve overlapping of generations, 8-nucleate asci, and mutations. We have not been able to identify any of our four M-genes with the gene for maltose fermentation, MA, described by Hestrin and Lindegren (I95I). As Lindegren probably has more than one M-gene in his material even though he does not admit this possibility, his MA gene may actually comprise more than one single gene.

\section{RAFFINOSE AND SUCROSE FERMENTATION}

Three genes responsible for the fermentation of raffinose have also been demonstrated in a single yeast type. Gilliland's hybrid Saccharomyces Italicus $\times S$. Chevalieri was found to be triply heterozygotic, segregating out according to the ratio of 7 raffinose fermenters : I nonfermenter (I 949). By analysing 20 asci of the hybrid, he found exactly 70 fermenters and Io non-fermenters-namely $\mathrm{I} 2$ asci yielding $4 \mathrm{R}: \mathrm{o}$, 6 asci yielding $3 \mathrm{R}: \mathrm{Ir}$, and 2 asci yielding $2 \mathrm{R}: 2 \mathrm{r}$. According to theoretical expectation, Io $6,8 \cdot 9$ and $0 \cdot 6$ respectively of the three types of asci should have occurred among the 20 analysed. It could not be a doubly heterozygotic segregation, and therefore there could hardly be any doubt that three gene pairs were involved.

A closer examination of this hybrid was undertaken (Winge and Roberts, I952), and we succeeded in separating the three R-genes in 
different yeast types just as we had previously done with the three maltose fermenting genes in $S$. cerevisiae.

Yeasts containing an $\mathrm{R}$-gene will split raffinose as well as sucrose. They produce a $\beta$-h-fructosidase, which splits off fructose from the raffinose molecule. The sucrose is fermented, leaving melibiose untouched. Hence, if only $R$ is present in the yeast, only one third of the raffinose is fermented.

The three genes for raffinose fermentation were called $R_{1}, R_{2}$ and $R_{3}$. If two yeast types containing unlike $R$-genes are crossed, e.g. $R_{1}$ and $R_{2}$, a double heterozygote, $R_{1} r_{1} R_{2} r_{2}$, will be produced, which will give a two-gene segregation. If two yeast types with identical R-genes are crossed the hybrid will of course be homozygotic as to the $\mathrm{R}$-gene in question, and consequently all offspring will be raffinosefermenting.

\section{CLOSE LINKAGE BETWEEN $M_{1}$ AND $R_{1}$}

Gilliland's original analyses of the hybrid Saccharomyces Italicus $\times$ $S$. Chevalieri disclosed a peculiar dependence between maltose and raffinose fermentation in the offspring of this hybrid, as all of his Io nonfermenters of raffinose were able to ferment maltose.

According to our present knowledge the following formula can be ascribed to this hybrid:

$$
\begin{aligned}
& \text { S. Italicus } \\
& M_{1} M_{1} G G r_{1} r_{1} r_{2} r_{2} r_{3} r_{3} \\
& \times \quad \text { S. Chevalieri } \\
& \mathrm{m}_{1} \mathrm{~m}_{1} \mathrm{~g}_{8} \mathrm{~g}_{8} \mathrm{R}_{1} \mathrm{R}_{1} \mathrm{R}_{2} \mathrm{R}_{2} \mathrm{R}_{3} \mathrm{R}_{3} \\
& \text { Hybrid } \\
& M_{1} m_{1} G_{8} R_{1} r_{1} R_{2} r_{2} R_{3} r_{3}
\end{aligned}
$$

The hybrid segregates out from every ascus 2 maltose-fermenters to 2 non-fermenters of maltose, and 2 rapid galactose-fermenters to 2: slow galactose-fermenters. As to raffinose fermentation, as we have already seen, there are different possibilities, some asci segregating out as $4: 0$, others as $3: 1$, and again others as $2: 2$. When, however, all nonfermenters of raffinose are found to be maltose fermenters, there must be some state of dependence between the $M_{1}$-gene and one or several genes for raffinose fermentation.

Our own experiments aimed at an explanation of this phenomenon.

Tetrad analyses of a hybrid of the above named formula (Winge and Roberts, I952) were in full accordance with Gilliland's results; we found $2: 2$ segregations as to maltose fermentation in all of the 37 asci analysed and 5 raffinose-negative single spore cultures, all of which were able to ferment maltose.

The explanation was found to be that the $M_{1}-m_{1}$ and $R_{1}-r_{1}$ gene pairs were closely linked. Through backcrossing the hybrid offspring to the raffinase-recessive type of the same formula as $S$. Italicus we produced the type $\overbrace{M_{1} m_{1} R_{1}} r_{1} r_{2} r_{2} r_{3} r_{3}$, and by analysing spore tetrads from this we obtained according to expectation a most peculiar segre- 
gation. From 62 asci analysed we found in every case the segregation $2 M_{1} r_{1}: 2 m_{1} R_{1}$-i.e., two single spore cultures fermenting maltose but not raffinose, and two cultures fermenting raffinose but not maltose. Furthermore we found one case of crossing-over-namely, an ascus segregating out as $1 M_{1} r_{1}: \mathrm{rm}_{1} \mathrm{R}_{1}: \mathrm{I} \mathrm{M}_{1} \mathrm{R}_{1}: \mathrm{Im}_{1} \mathrm{r}_{1}$.

By crossing the two cross-over types, which after diploidisation had the formula $M_{1} M_{1} R_{1} R_{1}$ and $m_{1} m_{1} r_{1} r_{1}$ respectively, we obtained a new hybrid, $\overparen{M_{1} m_{1}} R_{1} r_{1}$ with linkage in the opposite direction, since the two dominant genes were now linked. II tetrads from 4-spored asci were analysed and ro of these yielded the segregation $2 M_{1} R_{1}$ : $2 \mathrm{~m}_{1} \mathrm{r}_{1}$-i.e., two single spore cultures fermenting maltose as well as raffinose, and two cultures which were unable to ferment either of the two sugars. In one of the II asci crossing-over had occurred, and hence the segregation was $M_{1} R_{1}: m_{1} r_{1}: M_{1} r_{1}: m_{1} R_{1}$.

The linkage between $M_{1}$ and $R_{1}$ thus has been verified by analysing the phenomenon in the coupling phase as well as in the repulsion phase. The distance between the two genes has been calculated to be about I. 3 centimorgans.

As already stated, $M_{1}$ as well as the $R$-genes cause sucrose fermentation, but there is a distinct difference between them as to the fermentation interval-i.e., the time that elapses between the start of the fermentation test and the first appearance of $\mathrm{CO}_{2}$ in a Winge fermentometer. While an R-type is able to ferment sucrose within 5 hours, an $M_{1}$-type requires one to several days.

Summary. - As will be evident from these analytical results, all genes so far investigated are inherited in a strictly mendelian way. All fermenter genes, one for galactose fermentation, four for maltose fermentation, and three for raffinose and sucrose fermentation, show dominance. While the maltose fermenting genes $M_{1}$ and $M_{2}$ have been shown to have different biochemical effects, it remains to be determined whether $M_{3}$ and $M_{4}$ are different from $M_{1}$ and $M_{2}$ and whether or not the three $\mathrm{R}$-genes are biochemically identical.

\section{REFERENCES}

GILLILAND, R. B. I949. A yeast hybrid heterozygotic in four fermentation characters. Compt. Rend. Lab. Carlsberg, Sér. Physiol., 24, 347-356.

HESTRIN, SHLOMO AND LINDEGREN, c. c. 195I. Gene function in the homologous and heterologous induction of $\alpha$-glucosidases in yeast by $\alpha$-glucosides. Nature, I68, 913-9I4.

KILKENNY, B. G., AND HINSHELWOOD, CYRIL. 1951. Adaptation and mendelian segregation in the utilisation of galactose by yeast. Proc. Roy. Soc., Ser. B, 139, $73-85$.

LEUPOLD, URS. 1950. Die Vererbung von Homothallie und Heterothallie bei Schizosaccharomyces Pombe. Compt. Rend. Lab. Carlsberg, Sér. Physiol., 24, 381-480. LINDEGREN, CARL c. 1949. The yeast cell, its genetics and cytology. Educ. Publ., Inc., St. Louis. 
MUNDKUR, BALAjI D. I949a. " Long-term adaptation" and non-Mendelian inheritance in yeast. Nature, $164,6{ }_{4}-6{ }_{15}$.

MUNDKUR, BALAJI D. 1949b. Evidence excluding mutations, polysomy, and polyploidy as possible causes of non-Mendelian segregations in Saccharomyces. Missouri Bot. Gard. Ann., 36, 259-28o.

SPIEGELaran, s. I950. Modern aspects of enzymatic adaptation. The Enzymes, Vol. I, Part I, 267-306.

SPIEgelman, s., SUSSMAN, RACQUEl ROTMAN, AND PINSKa, E. I950. On the cytoplasmic nature of "long-term adaptation" in yeast. Proc. Nat. Acad. Sci., 36 , 59 I-6o6.

WINGE, Ö., AND ROBERTS, CATHERINE. I948. Inheritance of enzymatic characters in yeasts, and the phenomenon of long-term adaptation. Compt. Rend. Lab. Carlsberg, Sér. Physiol. 24, 263-315.

WINGE, ö., AND ROBERTS, CATHERINE. I950a. The polymeric genes for maltose fermentation in yeasts, and their mutability. Ibid., 25, 35-83.

WINGE, ö., AND ROBERTS, CATHERINE. I950 $b$. Identification of the gene for maltose fermentation in Saccharomyces Italicus. Nature, 166 , i I 14 .

WINGE, ö., AND ROBERTS, CATHERINE. 1952. The relation between the polymeric genes for maltose, raffinose, and sucrose fermentation in yeasts. Compt. Rend. Lab. Carlsberg, Sér. Physiol., 25, 14 1-1 7 I. 